Ramirez says that he now questions everything Schön has published. Colleagues have passed him eight more suspicious figures, including one that appeared in a Nature article not previously implicated (J.H.Schön, Ch. Kloc and B. Batlogg Nature $406,702 ; 2000)$. Lieber says that "any paper Schön was first author on since arriving at Bell Labs should be withdrawn".

Along with many other physicists, Myriam Sarachik of the City University of New York, president-elect of the American Physical Society (APS), believes that science is self-correcting, and that Schön's fraudulent work will eventually be either ignored or discarded. "The scientific method does ultimately weed out this sort of thing," she says.

Nevertheless, Sarachik says, the APS will review its misconduct policy in light of the Schön case and another high-profile fraud case involving the claimed discovery of element 118 (see Nature 418,261;2002). The society may also develop programmes to teach graduate students good laboratory practice, and designate an ombudsman to receive complaints of misconduct. "These latest episodes have made us realize that we'd better look at how we conduct our business," Sarachik says.

eight days on average during 2001, according to the Beasley report.

Schön's overnight success prompted the Max Planck Society to create a co-directorship especially for him at the Max Planck Institute for Solid State Research in Stuttgart. Eighteen months ago it initiated the lengthy Berufung process, a deliberation over a candidate's suitability that normally precedes a formal job offer.

"The procedure was, as usual, very careful and involved a lot of evaluators, none of whom raised objections," says the institute's managing director, Martin Jansen. "During interviews, Schön came over as a very kind and impressive personality who presented his work very convincingly."

Schön had signed no agreement with the Max Planck Society, but negotiations over his employment package had begun when suspicions about his work surfaced publicly. Negotiations were then put on ice, and Jansen has now recommended their cancellation.

Meanwhile, the DFG is studying the report's findings to see if the work that it supported involved misconduct. If so, says a spokeswoman, the DFG will immediately embark on its own inquiry. Sanctions for misuse of DFG funds range from a public warning to a demand for the return of grant funding.

\section{Saddam gives viewers double vision}

Quirin Schiermeier, Munich

Rumours that the Iraqi dictator Saddam Hussein uses doubles have been endorsed by a German face-recognition expert, who says he has evidence that television pictures of Saddam are really of his doppelgängers.

Commissioned by the German public TV network ZDF, Dieter Buhmann, a forensic scientist at Saarland University in Homburg, analysed 450 photographs of Saddam from the ZDF's archives and found significant deviations. "There is clear evidence that Saddam has used doubles in all but one appearance in public since 1998," he says.

Buhmann used an unpublished computer method that he first presented at the 2000

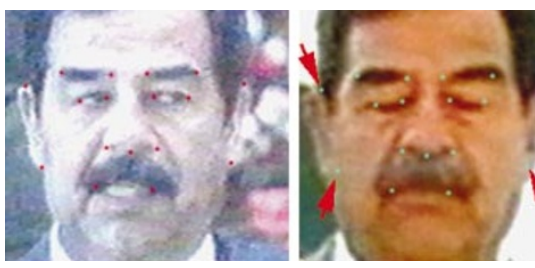

meeting of the International Association for Craniofacial Identification in Washington.

Chris Solomon, a biometricist at the University of Kent, says the results are plausible, but should be interpreted with caution. "You can never be totally sure whether or not two people are identical from the basis of photographs," he says.

\section{Former ImClone chief faces allegations of past misdeeds}

\section{Jonathan Knight, San Francisco}

A biotechnology entrepreneur who is facing high-profile charges of insider trading on the US stock market was repeatedly fired for suspected misconduct during his research career, according to allegations published by The Wall Street Journal.

A front-page story in the US newspaper on 27 September claims that Samuel Waksal, the former chief of biotech firm ImClone Systems in New York, was dismissed over questions of misconduct on four occasions in the 1970s and 1980s. Each time he quickly landed another research job at a prestigious institution, the story says. Scott Tagliarino, a spokesman for Waksal at Rubenstein Associates in New York, says that Waksal had no comment to make on the allegations.

But if true, the story highlights the difficulties faced by US institutions in trying to police scientific misconduct. University lawyers often prohibit faculty members from telling a suspect's prospective new employer that a misconduct investigation is under way, experts in scientific conduct say. And even if a scientist is found guilty, the university may keep quiet to avoid being sued for libel, says David Goodstein, a physicist and vice-provost of the California Institute of Technology who developed its policy on scientific misconduct.

Waksal is currently under investigation for allegedly informing friends, including homemaking celebrity Martha Stewart, of the impending rejection by federal regulators of ImClone's star cancer drug Erbitux, allowing them to cash out their stock.

According to the Journal article, he was ejected from a lab at Stanford University in 1974 on suspicion of lying about obtaining certain reagents. His employer at the time, biologist Leonard Herzenberg, confirmed this account in an interview on 30 September, adding that he told Waksal's next employer of his concerns by telephone with Waksal on the line - but that Waksal denied having lied and the warning went unheeded. "He was a real charmer," Herzenberger says. "He charmed everybody; people believed him."

But the problems continued, the Journal alleges. Waksal lost subsequent positions amid concerns about misconduct, it says, at the National Cancer Institute in 1977, at Tufts University School of Medicine in Boston in 1982, and at the Mount Sinai School of Medicine in New York in 1985 the year he founded ImClone. Henry Wortis, who collaborated with Waksal at Tufts, told Nature that he heard about the allegations of misconduct from several colleagues during the 1980s, after Waksal failed to deliver materials promised in a collaboration.

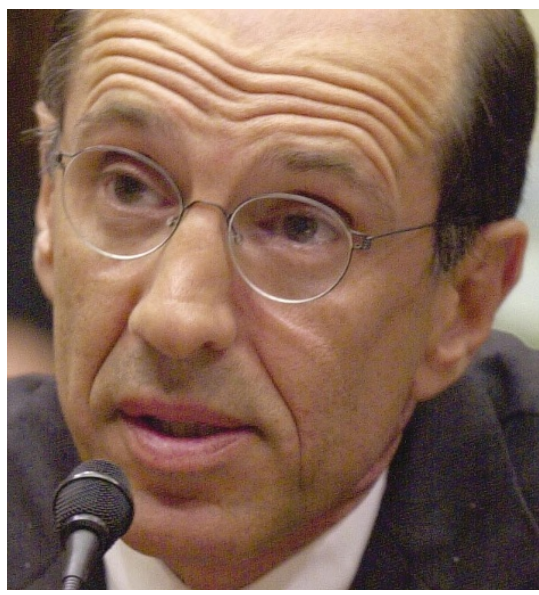

Samuel Waksal: questions raised over his career. 